\title{
Potcenjeni rizik promene kamatnih stopa
}

\author{
UDK: 336.781 .5 \\ Primljen: 20. 11. 2013. \\ Prihvaćen: 26. 11.2013. \\ Informativni prilog
}

\begin{abstract}
„Motriti na rizik promene kamatne stope”, danas je jedan od najvažnijih aktuelnih principa u oblasti finansijskih usluga. Dejstva faze primene niskih kamata su danas prioritet $u$ agendama službi finansijskog nadzora.

Obaranje kamatne stope od strane Evropske centralne banke (dalje u tekstu: ECB) u novembru 2013. godine na rekordno niskih $0,25 \%$ kritičari su obeležili kao „hladnu eksproprijaciju štediša.” Iako predstavlja jednu desetinu stope inflacije od 2,5\%, a koja se smatra umerenom na evropskom prostoru, građani gube motivaciju za štednju. Uz to, demotivaciju pojačavaju i zvanični stavovi, među kojima i stav visoke predstavnice Međunarodnog monetarnog fonda, koja predlaže da se za otplatu državnog duga koji traje decenijama i čije se posledice mere u milijardama evra, zadrži desetina štednog kapitala građana. Već se diskutuje i o negativnim kamatama, pri čemu se misli na naplatu troška za dugoročno „parkiranje” većih iznosa sredstava građana u bankama.
\end{abstract}

ECB se nada da će obaranjem kamate pospešiti konjukturu jer bi niža kamata intenzivirala široku potrošnju. Međutim, zbog napete situacije na tržištu rada ovaj efekat ili ne nastaje ili se pretvara u svoju suprotnost. Deo građana drži novac kod kuće, deo investira u upitne finansijske projekte sa navodno visokim prinosima. Zbog svega toga pivredni subjekti teže dolaze do bankarskih kredita za svoje investicije.

Klasična politika raspodele investiranja u ekonomiji osiguranja je, naročito u životnom osiguranju zbog aktuelnog snižavanja kamata, dovedena u nemilost. Branša mora da nađe način da se suprotstavi dugoročnoj pretnji obezvređenja osiguranja penzija. U prvom redu je potrebno putem informativnih kampanja delovati na privatna lica da u sektoru penzijskog osiguranja intenzivnije ne posežu za špekulativnim investicijama u nadi

\footnotetext{
* Univ. prof. dr Wolfgang Rohrbach je potpredsednik EUROPA NOSTRA AUSTRIA (Univerzitet Donau u Kremsu, Austrija), e-mail: consult@uniqa.rs.
}

da će na takav način brzo doći do dobiti. Krizne godine 2008. i 2009. su nam pokazale da se ovakvim investiranjem mogu samo naduvavati novi finansijski baloni sa skrivenim rizikom visokog gubitka.

Budući da u ekonomiji osiguranja „brzopotezne” mere finansijske politike donose slab ili nikakav rezultat, pristupiće se mega-dugoročnom projektu. Jednostavnije rečeno, osiguravači se iznova pozicioniraju u novom svetu investiranja: 80\% kompanija životnog osiguranja, neživotnog osiguranja kao i kompozitnih osiguravača namerava da promeni poslovni model kako bi ostvarili potreban prihod na uložena sredstva. Ovako piše izdanje časopisa Versicherungswirtschaft od 18. 11. 2013, ukazujući na studiju jedne od najpoznatijih svetskih kompanija za međunarodno investiranje i upravljanje fondovima - BlackRock.

Anketirano je 206 osiguravača širom sveta. Za 73\% svih anketiranih niži prinosi na tržištu kapitala glavni su razlog za promene. Marcus Severin, rukovodilac sektora osiguranja u kompaniji BlackRock u Nemačkoj i Austriji, piše u autorskom članku da su nemački osiguravači naročito otvoreni za promene. „Udeo nemačkih osiguravača koji misle da su niski prinosi na tržištu kapitala odlučujući za promene iznosi oko $80 \%$ i nešto je viši nego na globalnom nivou. Osiguravajuće kompanije srednje Evrope u pogledu izmene regulative osećaju jaču potrebu za promenom nego njihovi konkurenti u drugim državama."

U nove segmente tržišta sa fiksnim prihodima želi da investira $52 \%$ učesnika ankete; $58 \%$ je navelo da će izvršiti bolju diverzifikaciju svih klasa aktive u portfoliju; 47\% namerava da prilagodi poslovni okvir da bi taktičnije iskoristili tržišne šanse; $33 \%$ je spremno da uđe u veće rizike; $17 \%$ želi da koristi nelikvidne premije, na primer u okviru hedž-fondova, investicija u Private Equity ili infrastrukturu.

Nemački i austrijski osiguravači se, u poređenju sa drugima u svetu, naročito odlučno suočavaju sa izazovom novih uslova tržišta kapitala i novim propisima. $U$ 
6

poređenju sa međunarodnim konkurentima, nemački osiguravači delom koriste znatno veći udeo nelikvidnijih klasa aktive. Prilike za to pružaju banke koje su zbog povećanih oscilacija na tržištu kapitala i visokih zahteva za sopstvenim kapitalom prisiljene da redukuju bilans, a osiguravači bi trebali da ispune te praznine. Ovo bi važilo za kredite sa višim kamatama, kredite za nekret- nine, Leveraged Loans ili Colateralised Obligations na takozvanom tržištu sa fiksnim prihodima. 43\% kompanija u Nemačkoj koje je BlackRock anketirao, smatraju da će verovatno u sledećih dvanaest meseci investirati u zemlje u razvoju.

Prevod: Nela Bukorović, MA. e-mail:nela.bukorovic@yahoo.de 


\section{Unterschätztes Zinsänderungsrisiko}

UDK: 336.781 .5

Eingereicht: 20. 11. 2013.

Angenommen: 26. 11. 2013.

Informationstext

\begin{abstract}
„Das Zinsänderungsrisiko im Blick behalten”, lautet gegenwärtig einer der wichtigsten Grundsätze im Finanzdienstleistungsbereich. Die Auswirkungen der Niedrigzinsphase stehen derzeit auch weit oben auf der Agenda der Finanzaufsicht.
\end{abstract}

Die im November 2013 erfolgte Leitzinssenkung der Europäischen Zentralbank (EZB) auf ein Rekordtief von 0,25\% wird von Kritikern als „Kalte Enteignung der Sparer” bezeichnet. Selbst wenn die mit 2,5\% als moderat $\mathrm{zu}$ bezeichnende Inflationsrate im Euroraum das Zehnfache des Leitzinssatzes beträgt, schwindet bei den Bürgern dennoch die Sparmotivation. Verstärkt wird die Demotivation noch durch offizielle Stellungnahmen, wie jene einer hohen IWF-Repräsentantin, die zur Tilgung der milliardenschweren Folgen jahrzehntelanger staatlicher Schuldenpolitik vorschlug, ein Zehntel allen Sparkapitals der Bürger einzubehalten. Auch Negativzinsen werden bereits diskutiert. Darunter versteht man, dass für längerfristiges „Parken” größerer Geldbeträge in Banken, dem Sparer eine Art Lagergebühr verrechnet wird.

Mit Leitzinssenkungen hofft die EZB, die Konjunktur durch vermehrten Verbrauch von Wirtschaftsgütern seitens der breiten Bevölkerung anzukurbeln. Wegen der angespannten Situation auf dem Arbeitsmarkt bleibt diese Folgewirkung derzeit weitgehend aus oder kehrt sich bisweilen sogar ins Gegenteil. Die einen horten das Geld daheim. Andere investieren ihre Sparguthaben in fragwürdige Finanzprojekte mit angeblich hohen Renditemöglichkeiten. Dadurch wird es für Unternehmer noch schwieriger, Bankkredite für Investitionen zu erhalten.

Die klassische Veranlagungspolitik der Versicherungswirtschaft wird insbesondere im Lebensversicherungsbereich durch das derzeitige

\footnotetext{
* Univ. Prof. DDr Wolfgang Rohrbach ist stv. Geschäftsführer (Vize-Direktor) bei EUROPA NOSTRA AUSTRIA (Donau-Universität Krems); e-mail: consult@uniqa.rs.
}

Zinsänderungsrisiko stark in Mitleidenschaft gezogen. Die Branche muss der langfristig drohenden Entwertung der Pensions- und Altersvorsorge entgegenwirken.

Zunächst sollen durch Informationskampagnen Privatpersonen abgehalten werden, im Pensionsvorsorgesektor vermehrt $\mathrm{zu}$ spekulativen Investments zu greifen, in der Hoffnung dort schnell $\mathrm{zu}$ Renditen $\mathrm{zu}$ kommen. Aus den Krisenjahren 2008/09 wissen wir, dass in Wirklichkeit durch solche Investments nur neue Blasen aufgebaut werden, die ein hohes Verlustrisiko in sich bergen.

$\mathrm{Da}$ in der Versicherungswirtschaft grundsätzlich finanzpolitische "Schnellschüsse” wenig bis nichts bringen, wird ein Mega-Langzeitprojekt in Angriff genommen:

Vereinfacht ausgedrückt stellen sich Versicherer auf eine neue Investmentwelt ein

80 Prozent der Lebens-, Sach- und Kompositversicherer wollen ihr Geschäftsmodell ändern, um angemessene Renditen zu erwirtschaften. Das berichtete die Zeitschrift „Versicherungswirtschaft” in ihrer Ausgabe vom 18.11.2013 mit Verweis auf eine Studie des weltweit größten Vermögensverwalters BlackRock.

206 Versicherer wurden weltweit befragt. Für 73 Prozent der Unternehmen sind geringere Kapitalmarktrenditen der Hauptanlass für Veränderungen. Marcus Severin, Leiter des Versicherungsgeschäfts von BlackRock in Deutschland und Österreich schreibt in dem Autorenbeitrag, dass deutsche Versicherer für Veränderungen besonders offen seien. „Unter den deutschen Versicherern ist der Anteil derer, die geringere Kapitalmarktrenditen als ausschlaggebend für Veränderungen ansehen mit fast 80 Prozent noch etwas höher als global betrachtet." Die Versicherer Mitteleuropas spürten angesichts der regulatorischen Veränderungen die Notwendigkeit 
für Veränderungen stärker als ihre Wettbewerber aus anderen Ländern.

52 Prozent der Teilnehmer der Umfrage wollen in neue Segmente des Fixed Income-Marktes investieren. 58 gaben an, ihre Portfolios über sämtliche Anlageklassen hinweg besser zu diversifizieren. 47 Prozent haben die Absicht, ein Rahmenwerk zu erarbeiten, um vermehrt taktische Marktchancen zu nutzen. 33 Prozent sind bereit, höhere Risiken in Kauf zu nehmen. 17 Prozent möchten „Illiquiditätsprämien nutzen, zum Beispiel im Rahmen von Hedgefonds, Private Equity- oder Infrastruktur-Investments."

Die deutschen und österreichischen Versicherer gehen die Herausforderungen, die das neue Kapitalmarkt- und Regulierungsumfeld mit sich bringt, im internationalen Vergleich besonders entschlossen an. Gegenüber den internationalen Wettbewerbern nutzten die deutschen Versicherer teilweise in deutlich erhöhtem Maße illiquidere Anlageklassen. Die Chancen dazu böten die Banken, die aufgrund „erhöhter Volatilität am Kapitalmarkt und höheren Eigenkapitalanforderungen gezwungen seien, ihre Bilanzen zu verkürzen.” Die Versicherer könnten diese Lücke schließen. Das gelte für höher verzinste Kredite, Immobiliendarlehen. Leveraged Loans oder Colateralised Obligations im sog. Fixed-Income-Markt. 43 Prozent der deutschen Unternehmen, die BlackRock befragte, halten es für wahrscheinlich, dass sie innerhalb der nächsten zwölf Monate in Schwellenländern investieren. 